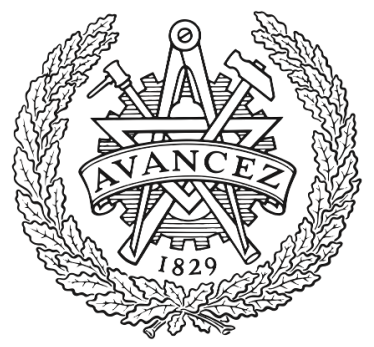

CHALMERS

UNIVERSITY OF TECHNOLOGY

\title{
Large Changes in Protonation of Weak Polyelectrolyte Brushes with Salt Concentration-Implications for Protein Immobilization
}

Downloaded from: https://research.chalmers.se, 2023-04-26 07:04 UTC

Citation for the original published paper (version of record):

Ferrand-Drake Del Castillo, G., Hailes, R., Dahlin, A. (2020). Large Changes in Protonation of Weak Polyelectrolyte Brushes with Salt

Concentration-Implications for Protein Immobilization. Journal of Physical Chemistry Letters, 11(13): 5212-5218. http://dx.doi.org/10.1021/acs.jpclett.0c01289

N.B. When citing this work, cite the original published paper. 


\title{
Large Changes in Protonation of Weak Polyelectrolyte Brushes with Salt Concentration-Implications for Protein Immobilization
}

\author{
Gustav Ferrand-Drake del Castillo, ${ }^{\dagger}$ Rebekah L. N. Hailes, ${ }^{\dagger}$ and Andreas Dahlin*
}

Cite This: J. Phys. Chem. Lett. 2020, 11, 5212-5218

Read Online

ABSTRACT: We report for the first time that the protonation behavior of weak polyelectrolyte brushes depends very strongly on ionic strength. The $\mathrm{p} K_{\mathrm{a}}$ changes by one $\mathrm{pH}$ step per order of magnitude in salt concentration. For low salt concentrations $(\sim 1 \mathrm{mM})$, a very high $\mathrm{pH}$ is required to deprotonate a polyacidic brush and a very low $\mathrm{pH}$ is required to protonate a polybasic brush. This has major consequences for interactions with other macromolecules, as the brushes are actually almost fully neutral when believed to be charged. We propose that many previous studies on electrostatic interactions between polyelectrolytes and proteins have, in fact, looked at other types of intermolecular forces, in particular, hydrophobic interactions and hydrogen bonds.

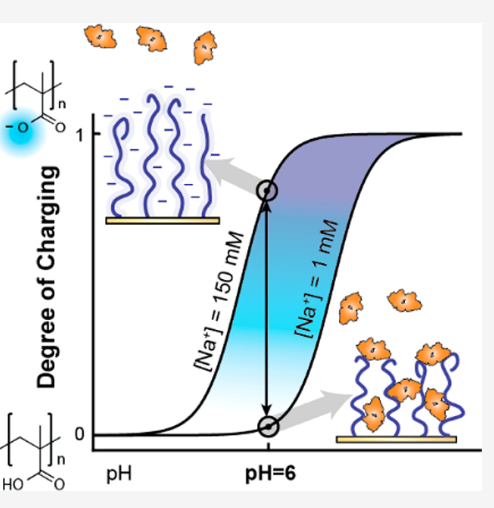

$\mathrm{P}$ olymer brushes formed by end-tethered chains at high grafting density provide a dense but flexible 3D support that contains a high number of functional groups. ${ }^{1}$ Weak polyelectrolyte (PE) brushes, that is, polymer brushes that contain weak acids or bases, undergo reversible protonation or deprotonation (between a neutral and a charged state) when the solution $\mathrm{pH}$ shifts across the $\mathrm{p} K_{\mathrm{a}}$ of the brush. ${ }^{2}$ This allows for electrostatic interactions to be tuned between the PEs or other charged macromolecules such as proteins. ${ }^{3,4}$ PE brushes are desirable because they combine a large binding capacity ${ }^{4}$ with reversible, charge-selective and structure-preserving immobilization. ${ }^{5,6}$ Applications include protein purification, ${ }^{4}$ drug delivery, ${ }^{7,8}$ enzyme immobilization, ${ }^{9,10}$ bioinspired nanoreactors, ${ }^{11}$ smart actuators, ${ }^{12}$ artificial joints, ${ }^{13,14}$ as well as bioelectronic devices ${ }^{15}$ and responsive interfaces. ${ }^{16}$ Polyelectrolytes are frequently found in biological systems, where they fulfill numerous functions such as lubrication and acting as receptors for cellular adhesion. ${ }^{17,18}$

Although it is well established that PE brushes can interact strongly with proteins and other macromolecules, open questions remain on the physical nature of the interaction. For instance, several studies have reported that proteins bind to PE brushes even when they carry the same net charge, ${ }^{19}$ that is, immobilization "on the wrong side" of the isoelectric point (pI) for the protein. Different explanations have been proposed for this phenomenon, such as interactions with local "patches" on the protein surface that do have the opposite charge to the PE brush. ${ }^{20-26}$ Alternatively, it has been suggested that the local environment inside the PE brush reverses the protein charge. ${ }^{26,27}$ Regardless, it is important to note that once a PE brush is charged, the ionic strength of the solution becomes a critical parameter for electrostatic interactions and also for the properties of the brush itself. ${ }^{28}$ Investigations to date on how the ionic strength influences PE brushes have focused on swelling/contraction and the role of ion valency. ${ }^{28-31}$ However, the direct influence from ionic strength on protonation behavior, that is, the brush $\mathrm{pK}_{\mathrm{a}}$ is generally overlooked. To the best of our knowledge, there is only one published study with data on the PE brush protonation state at different ionic strengths, but the salt was only varied from 10 to $100 \mathrm{mM}$, and no $\mathrm{pH}$ values around the brush $\mathrm{p} K_{\mathrm{a}}$ were included. $^{29}$ This gap in the literature is arguably quite surprising considering that it has been known for a very long time that the protonation behavior of PEs in solution does depend on ionic strength. ${ }^{32}$ Hence, one can expect that the degree of protonation of a weak $\mathrm{PE}$ brush (at a given $\mathrm{pH}$ ), which naturally determines its ability to participate in electrostatic interactions, will indeed depend on the ionic strength. Yet it appears that no study to date has properly investigated this effect. In fact, quite often a $\mathrm{p} K_{\mathrm{a}}$ for the brush is assumed without any clear motivation. ${ }^{20,23,26,33}$

In this work, we use multiple techniques to titrate weak PE brushes at different ionic strengths. The results consistently show that the $\mathrm{p} K_{\mathrm{a}}$ of (both acidic and basic) weak PE brushes does depend strongly on salt content. We investigate a cationic

Received: April 28, 2020

Accepted: June 9, 2020

Published: June 9, 2020 
PE brush poly(2-(diethylamino)ethyl methacrylate) (PDEA) and two anionic brushes poly(acrylic acid) (PAA) and poly(methacrylic acid) (PMAA) on planar gold surfaces (Scheme 1). At a given $\mathrm{pH}$, both the basic and the acidic

Scheme 1. Chemical Structures of the ATRP Initiator Attached to a Gold Surface (1) and Polymers: PDEA (2), PAA (3), and PMAA (4)

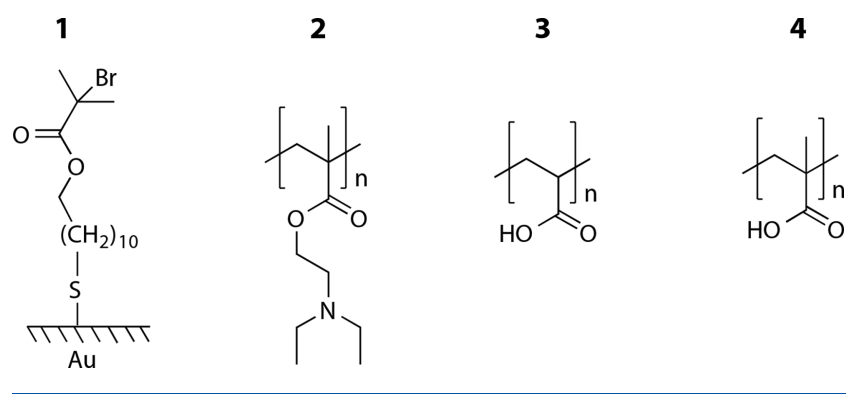

brushes are much less charged (the $\mathrm{p} K_{\mathrm{a}}$ is shifted) at lower ionic strength. We attribute this behavior to the high monomer density inside the brush and discuss analogies to the wellknown shift in $\mathrm{p} K_{\mathrm{a}}$ of a PE brush compared with the same polymer in solution. ${ }^{34-36}$ Our findings have very important consequences for protein immobilization because they show that as the salt concentration is lowered, which is typically done to promote electrostatic attraction, the brushes will actually lose their charge. This leads us to propose that the "electrostatic interactions" observed in many previous studies are, in fact, mistaken for other types of interactions (hydrogen bonds and hydrophobic), which occur with the neutral brush. Because protein binding is one of the main applications for PE brushes, our results are critical to consider. They are also important to know in order to control the $\mathrm{p} K_{\mathrm{a}}$ of PEs in general.
Weak PE brushes were prepared on gold surfaces by atom transfer radical polymerization (ATRP), as previously described. ${ }^{37}$ Note that we did not determine the grafting density and molecular weight, in part, because it is hard to get accurate values ${ }^{38}$ but mostly because we consider the monomer density inside the brush to be the relevant parameter for this study. On the basis of height probing in surface plasmon resonance (SPR), we determined the polymer volume fraction to be $10-50 \%$ depending on the protonation state and the monomer type, as expected (Figure S1). ${ }^{37}$ This is the typical monomer density for stretched chains in the brush configuration, ${ }^{31,39}$ and thus the results presented below should be relevant for PE brushes, in general.

The brushes were titrated in SPR at different salt concentrations (Figures $\mathrm{S} 2-\mathrm{S} 4$ ) by detecting the change in refractive index that occurs when the monomers become charged. ${ }^{37}$ The normalized SPR responses were fitted to sigmoidal functions to determine the effective $\mathrm{p} K_{\mathrm{a}}$ of the brush (Figure $1 \mathrm{~A}-\mathrm{C}$ ). We note that the $\mathrm{p} K_{\mathrm{a}}$ of groups at the top of the brush differs from that of groups deep inside the brush, which broadens the transition. ${ }^{35}$ Our values simply represent an average $\mathrm{p} K_{\mathrm{a}}$ value for the region of the brush that is within the evanescent field extension (up to $\sim 1 \mu \mathrm{m}$ at $980 \mathrm{~nm}$ ). All brushes analyzed in SPR had a hydrated thickness smaller than this (typically $100-500 \mathrm{~nm}$ ). ${ }^{37}$ The ionic strength was varied between $\sim 1$ and $\sim 500 \mathrm{mM}$. Remarkably, even though this represents a change in ionic strength of less than three orders of magnitude, the $\mathrm{p} K_{\mathrm{a}}$ changes by almost three units (Figure 1D) for all of the PE brushes. The same brush could be titrated multiple times without changing the SPR baseline, showing that the $\mathrm{pH}$ alterations did not cause any irreversible changes to the system. Only monovalent ions were included in the buffers to avoid cross-linking of chains. ${ }^{40}$ However, the SPR response may still contain a small contribution from changes in
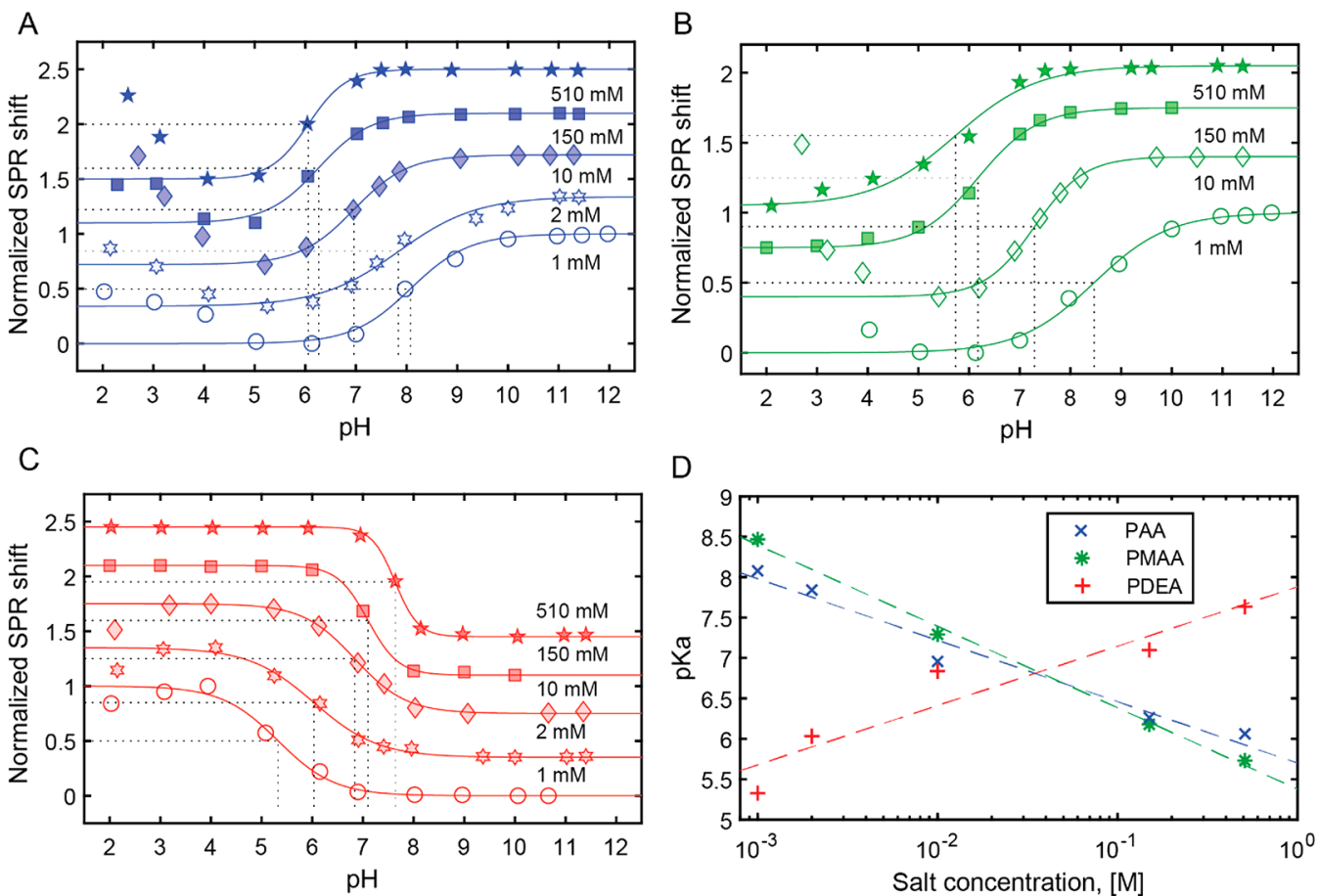

Figure 1. Determination of $\mathrm{p} K_{\mathrm{a}}$ values by SPR titration of (A) PAA, (B) PMAA, and (C) PDEA at different salt concentrations. (D) $\mathrm{p} K_{\mathrm{a}}$ versus salt concentration in log scale. 
A
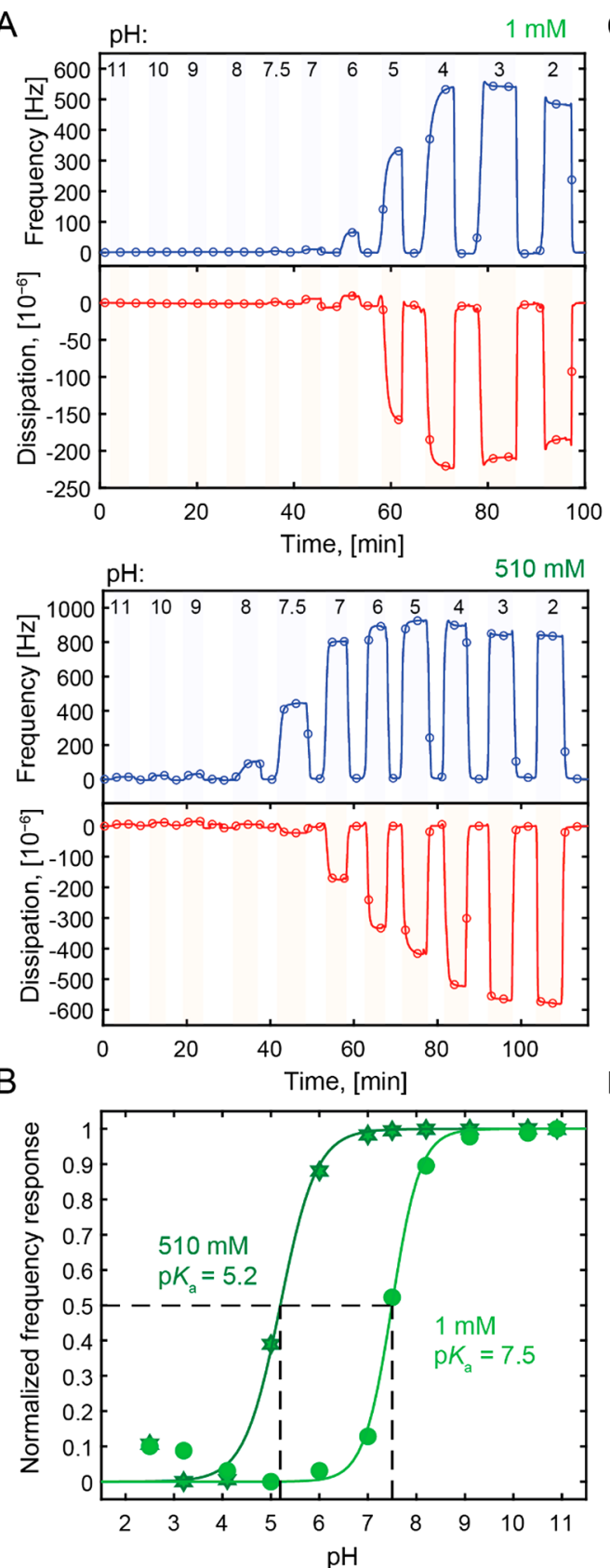

C
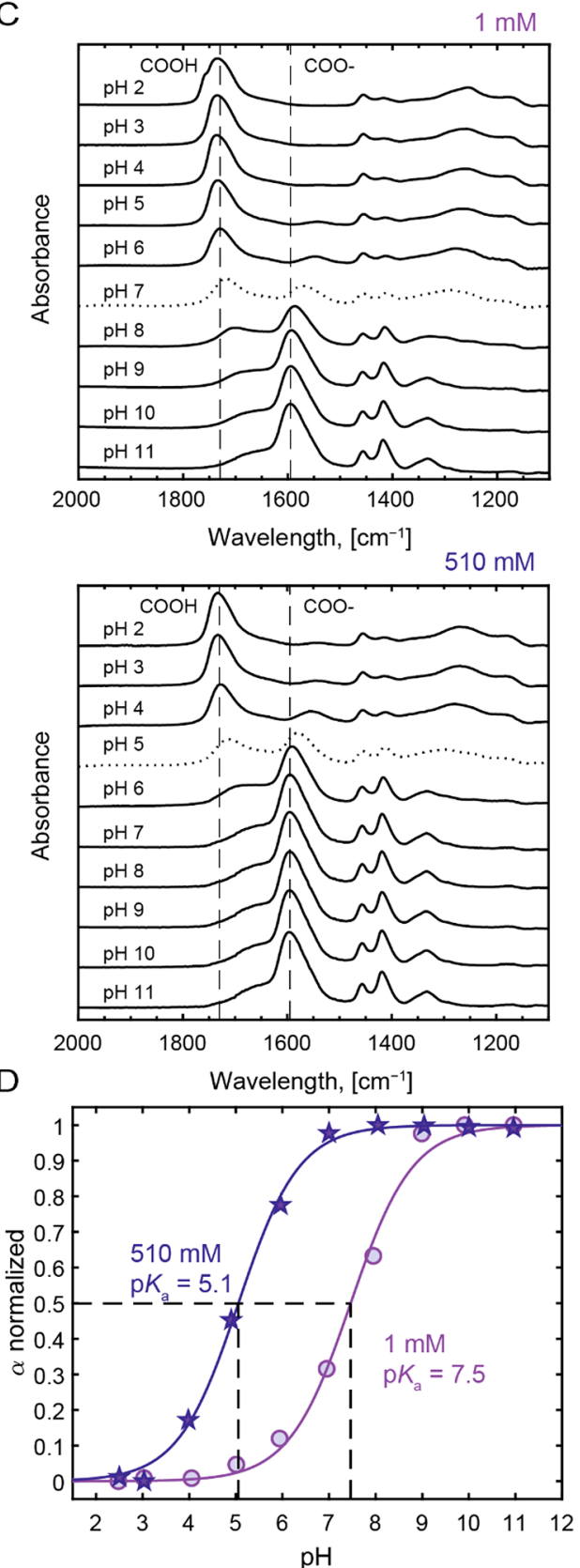

Figure 2. (A) QCMD titration experiments of PMAA brushes at 1 or $510 \mathrm{mM}$ salt. The running buffer is $\mathrm{pH} 12$, and injections are done with a lower $\mathrm{pH}$ (same salt content). (B) Comparison of the QCMD response as a function of $\mathrm{pH}$ for 1 (circles) and $510 \mathrm{mM}$ (stars), indicating the $\mathrm{pK}$ by dashed lines. (C) IR spectra of PAA exposed to $\mathrm{pH} 2-11$ solutions at 1 or $510 \mathrm{mM}$ salt. (D) Comparison of the dissociation obtained from the different bands as a function of $\mathrm{pH}$ for 1 (circles) and $510 \mathrm{mM}$ (stars), indicating the $\mathrm{p} K_{\mathrm{a}}$ by dashed lines.

brush extension/collapse with $\mathrm{pH} .{ }^{37}$ Therefore, we also used other methods to confirm the results.

Figure 2 shows results from titration using quartz crystal microbalance with dissipation monitoring (QCMD) and IR spectroscopy. The strong change in hydration of the PE brush as it becomes charged gives a large signal in QCMD, which can be used to determine $\mathrm{p} K_{\mathrm{a}} \cdot{ }^{34,41}$ We confirmed the SPR results by running titrations at two different ionic strengths (Figure $2 \mathrm{~A}$ and Figures S5 and S6), which reproduced the large change in $\mathrm{p} K_{\mathrm{a}}$. To get a direct measure of the protonation state, we also performed IR spectroscopy (Figure 2B) on PAA and PMAA, utilizing the shift in the carbonyl stretch (1700-1600 $\left.\mathrm{cm}^{-1}\right) .^{34,35}$ Spectral analysis (Figures S7 and S8) at low (1
$\mathrm{mM})$ and high $(510 \mathrm{mM})$ ionic strength confirmed the large change in $\mathrm{p} K_{\mathrm{a}}$ observed in SPR and QCMD. Note that because the methods are completely different in how they probe the degree of protonation, some variation can be expected (Table 1). Our main point is that all three methods show changes in $\mathrm{p} K_{\mathrm{a}}$ that are much larger (several $\mathrm{pH}$ units) than the experimental error within each method. When using the same method and the same polymer, sample to sample variation in $\mathrm{p} K_{\mathrm{a}}$ was estimated to be $0.2 \mathrm{pH}$ units (Figures S9 and S10).

The shifts in PE brush $\mathrm{p} K_{\mathrm{a}}$ with ionic strength are not surprising qualitatively speaking, as it is known that the $\mathrm{p} K_{\mathrm{a}}$ of polyacids in solution is a complex function of the salt 
Table 1. Comparison of $\mathrm{p} K_{\mathrm{a}}$ Values Obtained Using Three Different Techniques, SPR, QCMD, and IR, for All

Polyelectrolytes at the Highest $(510 \mathrm{mM})$ and Lowest (1 mM) Salt Concentrations Measured ${ }^{a}$

\begin{tabular}{|c|c|c|c|c|c|c|}
\hline & \multicolumn{2}{|c|}{ PDEA } & \multicolumn{2}{|c|}{ PMAA } & \multicolumn{2}{|c|}{ PAA } \\
\hline & $510 \mathrm{mM}$ & $1 \mathrm{mM}$ & $510 \mathrm{mM}$ & $1 \mathrm{mM}$ & $510 \mathrm{mM}$ & $1 \mathrm{mM}$ \\
\hline SPR & 7.6 & 5.3 & 5.7 & 8.5 & 6.1 & 8.1 \\
\hline QCMD & 7.5 & 5.9 & 5.2 & 7.5 & 5.0 & 7.0 \\
\hline IR & & & 5.7 & 7.7 & 5.1 & 7.5 \\
\hline
\end{tabular}

${ }^{a}$ Further salt concentrations measured by SPR can be found in Table S2.

concentration. ${ }^{42}$ On the contrary, quantitatively speaking, the effect is quite remarkable. For instance, the $\mathrm{p} K_{\mathrm{a}}$ of the carboxylic acid groups in the PMAA brush at $1 \mathrm{mM}$ salt is close to 9 . We see two possible explanations for the behavior, where the first is as follows: If the monomers become charged, then it introduces strong electrostatic repulsion inside the dense brush, that is, stronger than for a single chain in solution (which is less densely packed). This repulsion can be more or less screened depending on the amount of counterions available, which makes it more energetically unfavorable to have charged monomers at a lower ionic strength. Alternatively, there are always sufficient counterions inside the brush to screen the repulsion effectively, even at the lowest ionic strength, but the entropic penalty of their confinement becomes higher at lower salt concentration. Theory suggests that if the brush height is considerably higher than the Debye length, then one can assume that all counterions are confined in the brush. ${ }^{19}$ This is the case in our work because our longest Debye length is $\sim 10 \mathrm{~nm}$, whereas the brushes are hundreds of nanometers when hydrated. This picture is also supported by neutron reflectometry experiments showing that counterions only accumulate inside the brush, at least at $100 \mathrm{mM}$ salt. ${ }^{43}$ Therefore, we consider the counterion confinement to be the most likely explanation. (In the future, titrations at different temperatures could reveal more information about entropic and enthalpic contributions.)

Previous studies have shown that the $\mathrm{p} K_{\mathrm{a}}$ of a PE brush is higher than that for the same polymer in solution, which has been attributed to the higher monomer density in the brush. $^{34-36}$ We propose that this is also the explanation why the brush $\mathrm{p} K_{\mathrm{a}}$ changes so strongly with salt content. Indeed, for PEs in solution, the dependence on salt is smaller. ${ }^{32,42}$ Furthermore, our results suggest that monomer-monomer interactions are not likely to be the main cause of the changed protonation behavior of brushes compared with the same polymers in solution. For instance, if hydrogen bonds between $-\mathrm{COOH}$ groups ${ }^{44}$ were the main cause of the shift in protonation equilibrium, then it would be hard to see why the influence from the ionic strength would be so strong. Instead, electrostatic repulsion, or the counterion confinement that prevents it, seems to be the main free-energy penalty for a weak PE brush to assume its charged state at a low ionic strength. Note that throughout this study we have focused on equilibrium states rather than the kinetic aspects of protonation/deprotonation. Because SPR and QCMD operate in real time, it is possible to see how quickly the equilibrium is established when the bulk environment is changed. The equilibration took up to $\sim 15 \mathrm{~min}$ at 1 or $2 \mathrm{mM}$ salt, whereas it took $\sim 1 \mathrm{~min}$ at $510 \mathrm{mM}$. However, the kinetics were also very sensitive to the liquid exchange (flow rate and liquid cell geometry). Thus we believe systems with better liquid handling are required for detailed kinetic analysis.

Next, we looked at how the major change in $\mathrm{p} K_{\mathrm{a}}$ with salt alters the protein-binding properties of the PE brushes. As we have recently demonstrated, weak $\mathrm{PE}$ brushes can bind
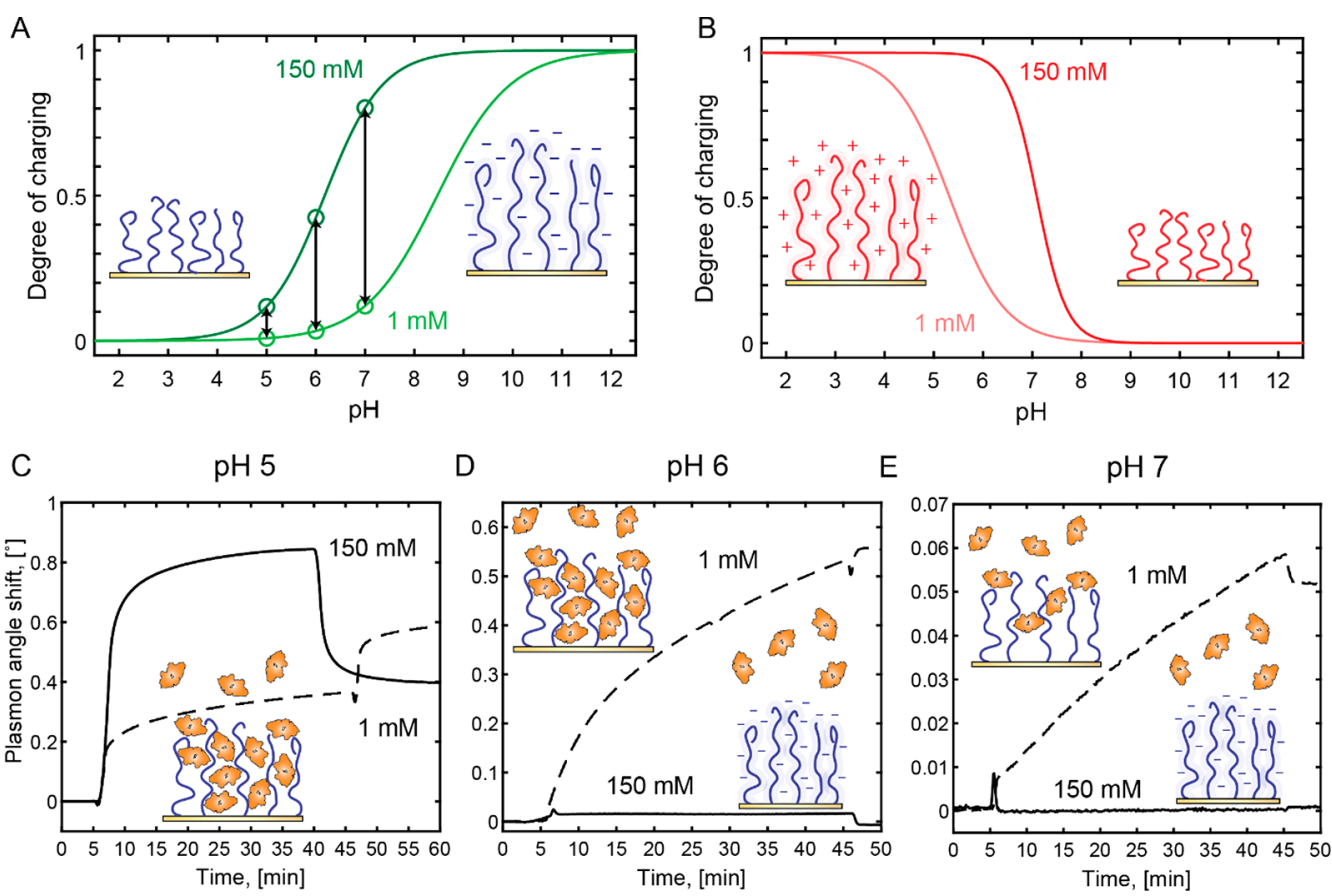

Figure 3. Effect of lowered ionic strength: Weak PE brushes (A) PMAA and (B) PDEA will become neutralized if the pH is close to physiological. Curves are fits to SPR titration data. Immobilization of BSA to PMAA measured by SPR at (C) pH 5, (D) pH 6, and (E) pH 7 in $150 \mathrm{mM}$ salt concentration (solid line) or $1 \mathrm{mM}$ salt concentration (dashed line). 
proteins very efficiently in their neutral state. For PAA and PMAA, this is due to hydrogen bonds, ${ }^{45}$ whereas hydrophobic interactions occur with PDEA. ${ }^{9}$ Regardless of the interaction, neutral PE brushes can immobilize large quantities of proteins. This becomes extremely important in light of the results above, which show that the brush has a strong tendency to be neutral at a lower ionic strength. Figure 3A,B shows the principle of salt content influencing the fraction of charged groups on the polymer. Especially around physiological $\mathrm{pH}$, both the acidic and the basic brushes will become almost fully neutralized when the ionic strength is lowered to $\sim 1 \mathrm{mM}$, starting from physiological $\mathrm{pH}$ or higher. On the basis of the titration data, quite extreme $\mathrm{pH}$ values ( $>11$ for PMAA and $<4$ for PDEA) are required to make the brush essentially fully charged at low ionic strength. Previous studies have indeed typically used low ionic strength, about two orders of magnitude below physiological $\mathrm{pH},{ }^{22-26,46}$ when performing (what was thought to be) electrostatic immobilization of proteins. They have also stayed close to physiological $\mathrm{pH}$, most likely because it was assumed that the brush $\mathrm{p} K_{\mathrm{a}}$ would not be so shifted. Therefore, we believe that many previous studies looking at protein binding to brushes actually had a very low fraction of charged groups and that other interactions were responsible for the observed binding. As mentioned, these are primarily hydrogen bonds ${ }^{45}$ and hydrophobic interactions, ${ }^{9}$ which are much less sensitive to ionic strength.

To confirm our hypothesis, we used SPR to analyze protein binding. Bovine serum albumin (BSA, pI 4.7) was introduced to a PMAA brush at different $\mathrm{pH}$ values and salt concentrations (Figure 3C-E). Immobilization of BSA occurs at $\mathrm{pH} \mathrm{5-7}$ at low ionic strength, when the brush has very few charged groups. The signal magnitudes in Figure 3C,D confirm that the proteins are assembling in multilayers inside the brush $^{9}$ (ternary adsorption). At $\mathrm{pH} \mathrm{7,} \mathrm{binding} \mathrm{becomes}$ weaker, which can be attributed to the presence of a small fraction of deprotonated groups as well as the increasingly negatively charged BSA; that is, the hydrogen-bond attraction competes with electrostatic repulsion. ${ }^{45}$ At physiological ionic strength, we observe binding only at $\mathrm{pH} 5$, when the degree of PMAA protonation is high, whereas no interaction is detected at all at $\mathrm{pH} 6$ to 7 . This can be attributed to the stronger electrostatic repulsion from the brush, in which the majority of carboxylic acid groups are now charged. We emphasize the binary results here (BSA interaction or not) rather than the signal magnitudes, as subtle shifts in $\mathrm{pH}$ (when close to the $\mathrm{p} K_{\mathrm{a}}$ ) or salt cause large differences in the amount of protein immobilized. In addition, the brush thickness and density will naturally influence the exact number of proteins that bind at a given $\mathrm{pH}$ and salt concentration.

From our results, it is clear that protein binding can depend on ionic strength in an indirect manner: Salt-induced on/off binding behavior, as has been previously observed, ${ }^{6,33}$ can be explained by changes in the protonation state due a shifted brush $\mathrm{p} K_{\mathrm{a}}$. Qualitatively, we also observed the same behavior for PDEA (Figure S11): At pH 4, glucose oxidase immobilization was completely suppressed at physiological ionic strength, but when the ionic strength was low, large quantities bound. We argue that the changes in the protonation state of the brushes as well as protein interactions with the neutral polymers need to be considered when interpreting such results. In general, electrostatic immobilization is not easy to perform; to reduce screening effects, a low salt concentration is preferred, but this implies either a quite high $\mathrm{pH}$ (polyacidic brush) or a quite low $\mathrm{pH}$ (polybasic brush). This may lead to denaturation for the protein, in addition to the fact that it becomes increasingly unlikely that the protein has the opposite charge to the PE brush.

In conclusion, we have shown that weak PE brushes strongly change their $\mathrm{p} K_{\mathrm{a}}$ value with ionic strength. The dependence is around one $\mathrm{pH}$ step per order of magnitude in salt concentration, and it occurs for both acidic and basic brushes. This has critical consequences for interactions between PE brushes and other molecules. When the ionic strength is low, extreme $\mathrm{pH}$ values (below $\sim 4$ or above $\sim 11$ ) are required to fully charge the polymers. This is because the electrostatic repulsion (or the entropic cost of counterion confinement) becomes very high inside a brush, which is due to the high monomer density. On the basis of these results, we propose that many previous studies that have aimed to investigate electrostatic interactions between PE brushes and proteins have, in fact, looked at hydrophobic interactions or hydrogen bonds. This should not in any way be interpreted as a falsification of effects such as electrostatic interaction "on the wrong side of the pI" of the protein. We simply claim that much experimental work has, most likely, been performed on brushes that were not very charged to begin with. Finally, we point out that we have studied the effects occurring inside the brush; that is, they originate from a high concentration of acidic/basic monomers and have nothing to do with the proximity to the underlying surface. Therefore, these findings have implications not only for PE brushes but also for other dense polymer constructs, such as hydrogels, biological coacervates, and any other supramolecular system composed of building blocks that contains a high density of weak acids or bases.

\section{ASSOCIATED CONTENT}

\section{(s) Supporting Information}

The Supporting Information is available free of charge at https://pubs.acs.org/doi/10.1021/acs.jpclett.0c01289.

Materials and Methods section and supplementary data (PDF)

\section{AUTHOR INFORMATION}

\section{Corresponding Author}

Andreas Dahlin - Department of Chemistry and Chemical Engineering, Chalmers University of Technology, 41296 Gothenburg, Sweden; 이이.org/0000-0003-1545-5860; Email: adahlin@chalmers.se

\section{Authors}

Gustav Ferrand-Drake del Castillo - Department of Chemistry and Chemical Engineering, Chalmers University of Technology, 41296 Gothenburg, Sweden

Rebekah L. N. Hailes - Department of Chemistry and Chemical Engineering, Chalmers University of Technology, 41296 Gothenburg, Sweden

Complete contact information is available at:

https://pubs.acs.org/10.1021/acs.jpclett.0c01289

\section{Author Contributions}

${ }^{\dagger}$ G.F.-D.d.C. and R.L.N.H. contributed equally.

\section{Notes}

The authors declare no competing financial interest. 


\section{ACKNOWLEDGMENTS}

This work was financed by the Knut \& Alice Wallenberg Foundation (2015.0161), the Erling-Persson Family Foundation (Starting Grant 2017), and the Swedish Research Council (2016-03319).

\section{REFERENCES}

(1) Chen, W.-L.; Cordero, R.; Tran, H.; Ober, C. K. 50th Anniversary Perspective: Polymer Brushes: Novel Surfaces for Future Materials. Macromolecules 2017, 50, 4089-4113.

(2) Netz, R. R.; Andelman, D. Neutral and charged polymers at interfaces. Phys. Rep. 2003, 380, 1-95.

(3) Dai, J.; Bao, Z.; Sun, L.; Hong, S. U.; Baker, G. L.; Bruening, M. L. High-capacity binding of proteins by poly(acrylic acid) brushes and their derivatives. Langmuir 2006, 22, 4274-4281.

(4) Kusumo, A.; Bombalski, L.; Lin, Q.; Matyjaszewski, K.; Schneider, J. W.; Tilton, R. D. High capacity, charge-selective protein uptake by polyelectrolyte brushes. Langmuir 2007, 23, 4448-4454.

(5) Takasu, K.; Kushiro, K.; Hayashi, K.; Iwasaki, Y.; Inoue, S.; Tamechika, E.; Takai, M. Polymer brush biointerfaces for highly sensitive biosensors that preserve the structure and function of immobilized proteins. Sens. Actuators, B 2015, 216, 428-433.

(6) Delcroix, M. F.; Laurent, S.; Huet, G. L.; Dupont-Gillain, C. C. Protein Adsorption can be Reversibly Switched on and off on Mixed PEO/PAA Brushes. Acta Biomater. 2015, 11, 68-79.

(7) Katz, E.; Pingarron, J. M.; Mailloux, S.; Guz, N.; Gamella, M.; Melman, G.; Melman, A. Substance Release Triggered by Biomolecular Signals in Bioelectronic Systems. J. Phys. Chem. Lett. 2015, 6, 1340-1347.

(8) Stuart, M. A.; Huck, W. T.; Genzer, J.; Muller, M.; Ober, C.; Stamm, M.; Sukhorukov, G. B.; Szleifer, I.; Tsukruk, V. V.; Urban, M.; Winnik, F.; Zauscher, S.; Luzinov, I.; Minko, S. Emerging Applications of Stimuli-Responsive Polymer Materials. Nat. Mater. 2010, 9, 101113.

(9) Ferrand-Drake del Castillo, G.; Koenig, M.; Muller, M.; Eichhorn, K.-J.; Stamm, M.; Uhlmann, P.; Dahlin, A. Enzyme Immobilization in Polyelectrolyte Brushes: High Loading and Enhanced Activity Compared to Monolayers. Langmuir 2019, 35, $3479-3489$

(10) Gustafsson, H.; Kuchler, A.; Holmberg, K.; Walde, P. Coimmobilization of Enzymes with the Help of a Dendronized Polymer and Mesoporous Silica Nanoparticles. J. Mater. Chem. B 2015, 3, 6174-6184.

(11) Kuchler, A.; Yoshimoto, M.; Luginbuhl, S.; Mavelli, F.; Walde, P. Enzymatic reactions in confined environments. Nat. Nanotechnol. 2016, 11, 409-420.

(12) Huck, W. T. S. Responsive Polymers for Nanoscale Actuation. Mater. Today 2008, 11, 24-32.

(13) Yu, J.; Mao, J.; Yuan, G.; Satija, S.; Jiang, Z.; Chen, W.; Tirrell, M. Structure of Polyelectrolyte Brushes in the Presence of Multivalent Counterions. Macromolecules 2016, 49, 5609-5617.

(14) Yu, J.; Jackson, N. E.; Xu, X.; Morgenstern, Y.; Kaufman, Y.; Ruths, M.; de Pablo, J. J.; Tirrell, M. Multivalent Counterions Diminish the Lubricity of Polyelectrolyte Brushes. Science 2018, 360, 1434-1438.

(15) Privman, M.; Tam, T. K.; Pita, M.; Katz, E. Switchable Electrode Controlled by Enzyme Logic Network System: Approaching Physiologically Regulated Bioelectronics. J. Am. Chem. Soc. 2009, 131, 1314-1321.

(16) Tam, T. K.; Pita, M.; Trotsenko, O.; Motornov, M.; Tokarev, I.; Halamek, J.; Minko, S.; Katz, E. Reversible "Closing" of an Electrode Interface Functionalized with a Polymer Brush by an Electrochemical Signal. Langmuir 2010, 26, 4506-4513.

(17) Lee, S.; Spencer, N. D. Materials Science. Sweet, Hairy, Soft, and Slippery. Science 2008, 319, 575-576.

(18) Attili, S.; Borisov, O. V.; Richter, R. P. Films of End-Grafted Hyaluronan are a Prototype of a Brush of a Strongly Charged,
Semiflexible Polyelectrolyte with Intrinsic Excluded Volume. Biomacromolecules 2012, 13, 1466-1477.

(19) Ballauff, M.; Borisov, O. Polyelectrolyte Brushes. Curr. Opin. Colloid Interface Sci. 2006, 11, 316-323.

(20) Yigit, C.; Kanduc, M.; Ballauff, M.; Dzubiella, J. Interaction of Charged Patchy Protein Models with Like-Charged Polyelectrolyte Brushes. Langmuir 2017, 33, 417-427.

(21) Koenig, M.; Bittrich, E.; Konig, U.; Rajeev, B. L.; Muller, M.; Eichhorn, K. J.; Thomas, S.; Stamm, M.; Uhlmann, P. Adsorption of Enzymes to Stimuli-Responsive Polymer Brushes: Influence of Brush Conformation on Adsorbed Amount and Biocatalytic Activity. Colloids Surf., B 2016, 146, 737-745.

(22) Bittrich, E.; Rodenhausen, K. B.; Eichhorn, K.-J.; Hofmann, T.; Schubert, M.; Stamm, M.; Uhlmann, P. Protein Adsorption on and Swelling of Polyelectrolyte Brushes: A Simultaneous EllipsometryQuartz Crystal Microbalance Study. Biointerphases 2010, 5, 159-167.

(23) Kusumo, A.; Bombalski, L.; Lin, Q.; Matyjaszewski, K.; Schneider, J. W.; Tilton, R. D. High Capacity, Charge-Selective Protein Uptake by Polyelectrolyte Brushes. Langmuir 2007, 23, 4448-4454.

(24) Hollmann, O.; Gutberlet, T.; Czeslik, C. Structure and Protein Binding Capacity of a Planar PAA Brush. Langmuir 2007, 23, 13471353.

(25) Hollmann, O.; Czeslik, C. Characterization of a Planar Poly(acrylic acid) Brush as a Materials Coating for Controlled Protein Immobilization. Langmuir 2006, 22, 3300-3305.

(26) Wittemann, A.; Haupt, B.; Ballauff, M. Adsorption of Proteins on Spherical Polyelectrolyte Brushes in Aqueous Solution. Phys. Chem. Chem. Phys. 2003, 5, 1671-1677.

(27) de Vos, W. M.; Leermakers, F. A. M.; de Keizer, A.; Cohen Stuart, M. A.; Kleijn, J. M. Field Theoretical Analysis of Driving Forces for the Uptake of Proteins by Like-Charged Polyelectrolyte Brushes: Effects of Charge Regulation and Patchiness. Langmuir 2010, 26, 249-259.

(28) Liu, G. Tuning the Properties of Charged Polymers at the Solid/liquid Interface with Ions. Langmuir 2019, 35, 3232-3247.

(29) Zhang, J.; Kou, R.; Liu, G. Effect of Salt Concentration on the $\mathrm{pH}$ Responses of Strong and Weak Polyelectrolyte Brushes. Langmuir 2017, 33, 6838-6845.

(30) Guo, X.; Ballauff, M. Spatial Dimensions of Colloidal Polyelectrolyte Brushes as Determined by Dynamic Light Scattering. Langmuir 2000, 16, 8719-8726.

(31) Willott, J. D.; Murdoch, T. J.; Humphreys, B. A.; Edmondson, S.; Webber, G. B.; Wanless, E. J. Critical Salt Effects in the Swelling Behavior of a Weak Polybasic Brush. Langmuir 2014, 30, 1827-1836.

(32) Arnold, R. The Titration of Polymeric Acids. J. Colloid Sci. 1957, 12, 549-556.

(33) Czeslik, C.; Jackler, G.; Hazlett, T.; Gratton, E.; Steitz, R.; Wittemann, A.; Ballauff, M. Salt-Induced Protein Resistance of Polyelectrolyte Brushes Studied Using Fluorescence Correlation Spectroscopy and Neutron Reflectometry. Phys. Chem. Chem. Phys. 2004, 6, 5557-5563.

(34) Schuwer, N.; Klok, H.-A. Tuning the pH Sensitivity of Poly(methacrylic acid) Brushes. Langmuir 2011, 27, 4789-4796.

(35) Dong, R.; Lindau, M.; Ober, C. K. Dissociation Behavior of Weak Polyelectrolyte Brushes on a Planar Surface. Langmuir 2009, 25, 4774-4779.

(36) Currie, E. P. K.; Sieval, A. B.; Avena, M.; Zuilhof, H.; Sudhölter, E. J. R.; Cohen Stuart, M. A. Weak Polyacid Brushes: Preparation by LB Deposition and Optically Detected Titrations. Langmuir 1999, 15, $7116-7118$.

(37) Ferrand-Drake del Castillo, G.; Emilsson, G.; Dahlin, A. Quantitative Analysis of Thickness and pH Actuation of Weak Polyelectrolyte Brushes. J. Phys. Chem. C 2018, 122, 27516-27527.

(38) Kang, C.; Crockett, R.; Spencer, N. D. The Influence of Surface Grafting on the Growth Rate of Polymer Chains. Polym. Chem. 2016, 7, 302-309.

(39) Santonicola, M. G.; de Groot, G. W.; Memesa, M.; Meszynska, A.; Vancso, G. J. Reversible pH-Controlled Switching of Poly- 
(methacrylic acid) Grafts for Functional Biointerfaces. Langmuir 2010, 26, 17513-17519.

(40) Xu, X.; Mastropietro, D. J.; Ruths, M.; Tirrell, M. V.; Yu, J. IonSpecific Effects of Divalent Ions on the Structure of Polyelectrolyte Brushes. Langmuir 2019, 35, 15564-15572.

(41) Hollingsworth, N. R.; Wilkanowicz, S. I.; Larson, R. G. Salt- and $\mathrm{pH}$-induced Swelling of a Poly(acrylic acid) Brush via Quartz Crystal Microbalance w/dissipation (QCM-D). Soft Matter 2019, 15, 78387851.

(42) Borukhov, I.; Andelman, D.; Borrega, R.; Cloitre, M.; Leibler, L.; Orland, H. Polyelectrolyte Titration: Theory and Experiment. J. Phys. Chem. B 2000, 104 (47), 11027-11034.

(43) Tran, Y.; Auroy, P.; Lee, L. T.; Stamm, M. Polyelectrolyte Brushes: Counterion Distribution and Complexation Properties. Phys. Rev. E: Stat. Phys., Plasmas, Fluids, Relat. Interdiscip. Top. 1999, 60, 6984-6990.

(44) Swift, T.; Swanson, L.; Geoghegan, M.; Rimmer, S. The pHresponsive Behaviour of Poly(acrylic acid) in Aqueous Solution is Dependent on Molar Mass. Soft Matter 2016, 12, 2542-2549.

(45) Ferrand-Drake del Castillo, G.; Hailes, R. L. N.; Adali-Kaya, Z.; Robson, T.; Dahlin, A. Generic High-Capacity Protein Capture and Release by pH Control. Chem. Commun. 2020, 56, 5889-5892.

(46) Dai, J. H.; Bao, Z. Y.; Sun, L.; Hong, S. U.; Baker, G. L.; Bruening, M. L. High-Capacity Binding of Proteins by Poly(acrylic acid) Brushes and their Derivatives. Langmuir 2006, 22, 4274-4281. 